This paper has been retracted. A Retraction notice was published on 28 June 2016 at Int. J. Environ. Res. Public Health 2016, 13, 646; doi:10.3390/ijerph13070646
International Journal of

Environmental Research and Public Health

ISSN 1661-7827

www.ijerph.org

(c) 2008 by MDPI

\title{
Sanitary Conditions of Public Swimming Pools in Amman, Jordan
}

\author{
${ }^{2}$ Public Health Inspector, Health Department, Al-Rumtha, Jordan \\ *Correspondence to Dr. Atallah Rabi. E-mail: rabi@just.edu.jo
}

Atallah Rabi ${ }^{1 *}$, Yousef Khader ${ }^{1}$, Ahmed Alkafajei ${ }^{1}$ and Ashraf Abu Aqoulah ${ }^{2}$

${ }^{1}$ Department of Public Health, Faculty of Medicine, Jordan University of Science and Technology (JUST), Irbid, Jordan.

Received: 16 January 2008 / Accepted: 20 May 2008 / Published: 30 September 2008

Abstract: This study was carried out in the summer of 2005 and investigated all of aetive public swimming pools (85 out of 93) in Amman, the capital of Jordan. The aim of this study was to find out if these swimming pools are in compliance with Jordanian Standards for Swimming Pools Water (S1562/2004). The pools were surveyed against the water microbial quality and other physicochemical parameters indicated in the standards. Two samples from each pool were collected for microbial analysis and pools monitoring were carried out during the afternoon of the weekends when the pools are most heavily used. The results indicated overall poor compliance with the standards. Compliance of the pools water to the microbial parameters was $56.5 \%$, for residual chlorine $49.4 \%$, for $\mathrm{pH} 87.7 \%$, water temperature $48.8 \%$, and bathing load $70.6 \%$. The results also indicated that water microbial quality deteriorated with time. Multivariate analysis showed significant association of water contamination with time of sample collection, residual chlorine, water temperature and load of swimmers. The poor compliance was attributed to lack of proper disinfection, staff training, proper maintenance, and timely inspection.

Keywords: Swimming pools, sanitary standards, water quality, Jordan, Amman

\section{Introduction}

Swimming, one of the fun, active, and a healthy way especially in summer where a exceeds $35^{\circ} \mathrm{C}\left(95^{\circ}\right)$ exceeds $35^{\circ} \mathrm{C}\left(95^{\circ} \mathrm{F}\right)$ most of summer days. Therefore, swimming is a great way to relax and beat the summer heat. Pools are good recreationalplaces where one can practice swimming as one of the popular sperts. The importance of swimming pools in Jordan as a recreational tool acquires special importance. These pools are the only place for swimming for most of the Jordanians especially those living in Amman, the Jordanian capital, with a population of more than 2 million, or about $40 \%$ of the Jordanian population. The reason for that is because marine water is not easily accessible. The nearest normal sea water is the Red Sea which is more than $300 \mathrm{Km}$ away from Amman.

In spite of the importance and popularity of swimming pools in summer, they have been identified as posing a risk for infection by certain fast-growing environmental bacteria [1]. The most common disease caused by swimming pools is diarrhea. A person with diarrhea can easily contaminate the pool with fecal matter.
Diarrhea is then spread when swimmers swallow this contaminated pool water. Moreover, swimming pools are used by a wide variety of people with different health conditions and are thus more susceptible to infection from opportunistic bacteria.

Bathers contaminate the water with large amounts of microorganisms as a result of bathers' secretions containing microorganisms which are shed from skin, mouth, nose and throat, urine, feces or by contaminated objects and clothes, making water a possible vehicle for the dissemination of diseases among swimmers. From the skin alone hundreds of millions of bacteria are rinsed during swimming [2, 3]. If left untreated, these pollutants will build up in water increasing the risk of infection to the swimmers.

Microorganisms that are usually connected to swimming pools include Pseudomonas Aeruginosa, Legionellae, Cryptosporidium parvum, Giardia, Microsporidia, Dermatophytes and Keratinophilic fungi and Molluscum Contagiosum [4-11].

Swimming pools are well-documented transmission vehicle for infectious diseases throughout the world [2]. These diseases include: 
a. Bacterial diseases, such as, skin and eye infections, respiratory wound infections, gastroenteritis, folliculitis, external otitis, and corneal ulcer cheratitis (in wearers of contact lenses), swimming pool granuloma, cholera, paratyphoid fever, typhoid fever, hot-foot syndrome and haemolytic uraemic syndrome:

b. Parasitic diseases, such as, chronic diarrhea, cryptosporidiosis, giardiasis, and dysentery: Fungal diseases, such as, a tinea pedis, superfacial mycoses, opportunistic mycoses, and hypersensitivity pneumonitis:

c. Viral diseases, such as, a molluscum contagiosum infection, Hepatitis A, poliomyelitis, echovirus infection, and pharyngitis [2-6, 9-15].

Because of the health hazards of swimming pools, it is essential to monitor water quality in swimming pools to insure safety of water and complience with standards. The control of infection risks does require continuous water quality surveillance, assessment of the efficiency of treatment and disinfection processes, changes in chemical and physical characteristics of pools and evaluation of the behaviour of swimmers which may affect the water quality. Such water quality also depends on the total number of swimmers in the pools at any time, water temperature and environmental conditions.

Ministry of Health carries out a water quality monitoring program which includes analysis of water samples and reporting on the swimming characteristics. It is beleived that such monitoring prgram does not reflect the quality of water because water samples are collected during the work days (Sunday and during working hours 8:00 pm- 2:00 occurs when the bathers, especially who are brought by their working The highest number of bathers are weekends (Friday and Saturday) it is believed that approp water quality evaluation should be carried out on the weekend days to reflect the water quality and the consequent heath risk when peak number bathers are using the pools.

This study was performed to ascertain the microbiological quality of swimming pool waters of Amman, in addition to some of the physical and chemical quality parameters and to find out if the swimming pools of Amman are in compliance with Jordanian Standards for Swimming Pools Water (JS 1562/2004), This study will provide baseline data about the quality of public swimming pools in Amman and identifies the risk factors associated with using these pools. It will suggest corrective measures to protect all swimmers from health hazards associated with swimming in unsanitary pools.

\section{Methods and Materials}

This study was conducted during the swimming season (June 18 - August 13, 2005). Amman has 93 swimming pools which constitute $65 \%$ of the total pools in Jordan. The study covered 85 swimming pools representing all operating swimming pools in Amman. The other 8 pools were not in operation at the time of the study. One hundred and seventy samples were collected from these pools. Two samples from each pool were collected at two different weekend days (85 in Saturday and 85 in Friday) and at different times of the day (111 at 12-3 PM, 32 at 3-4 PM, and 27 at 4-5 PM) from each swimming pool. Days and time of sampling were selected because the number of swimmers was at maximum.

To insure the uniformity of water quality throughout the pool and to get a more representative sample, each water sample was collected at a depth of $50 \mathrm{~cm}$ of water surface and from four different points about one meter away from the pool edge. These samples were taken in $250 \mathrm{ml}$ sterilized dark-colored glass bottles containing few drops of sodium thiosulphate to serve as inhibitor of chlorine action after sampling. The samples were transported refrigerated in ice box to the laboratory where they were analyzed, using multiple tube technique, for total coliform and fecal coliform test within 6 hours after collection. The sample was considered contaminated if it contained total coliform (TC) $1.1 \mathrm{MPN} / 100 \mathrm{ml}$, with or without fecal coliform, when tested by multi-tube method [19].

On the other hand, a separate sample was collected for on-site chemical analysis. The parameters measured included water temperature; $\mathrm{pH}$, residual chlorine and transparency were measured. The microbial analysis for total coliform, and fecal coliform and chemical parameter measurement measurements were done according to the standard methods. ${ }^{20}$

A pre-tested chick-list was prepared based on Jordanian Standard for Swimming Pools Water (JS 1562/2004) [18] and filled by direct observation, interview with swimming pool operator, field measurements in swimming pools area. The number of swimmers and swimming bathing load were noted.

Data about pools and swimmers included: Type of pool, age and gender of pool users, taking shower before swimming, disinfection of feet by using disinfection liquid before stepping in the pool, cleanness of the pool water from floating material and availability of guidance board including health requirements. Swimming pool operators were interviewed for information about: recycling of the swimming pool water, treatment method of swimming pools water, method of disinfection and type of chlorine used. Data were analyzed using Statistical Package for Social Sciences (SPSS, version 11.5). Swimming pools, swimmers and sanitary parameters were described using frequencies and cross tabulation. Binary logistic regression was used to determine factors associated with TC > 1.1 MPN/100 ml. Comments about statistical significance refer to probability of less than 0.05 .

\section{Results}

\section{Characteristics of Swimming Pools}

The characteristics of the public swimming pools in Amman /Jordan that were open at the time of the study are 
depicted in Table 1. Sixty percent of swimming pools were outdoors. More than $60 \%$ of swimming pools were used by males and females of all ages, while one quarter of pools was used exclusively by males. About one-half of the swimming pools had water volume of more than 150 $\mathrm{m}^{3}$. Most of the pools (79\%) were disinfected manually by chlorine powder. Almost all (98\%) of swimming pools had wardrobes available for swimmers. Guidance board was available in $72 \%$ of pools. Adherence to bathing load was followed in $71 \%$ of pools. More than half $(53.5 \%)$ of swimming pools had a number of swimmers, at the time of data collection, $>20$ persons. All swimming pools were free from floating material and were clean during visits. None of the surveyed public swimming pool was in full compliance with the Jordanian Standards for Swimming Pools Water (JS 1562/2004).

Table 1: Characteristics of the Public Swimming Pools in Amman/ Jordan

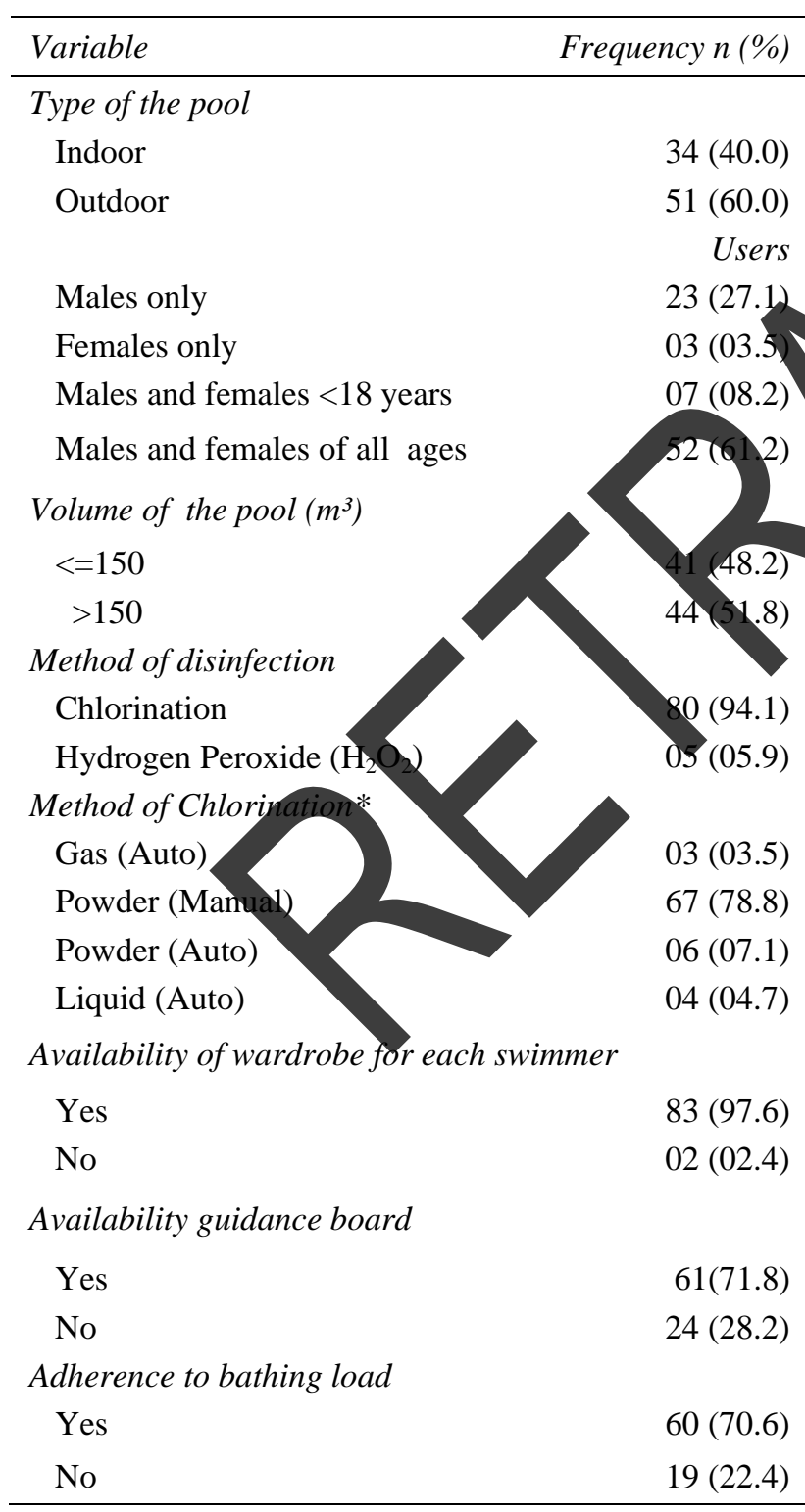

\section{Sanitary Parameters}

Table 2 shows the sanitary parameters of studied swimming pools. Less than half (48.8\%) of the swimming pools met the water temperature standard $\left(22-27^{\circ} \mathrm{C}\right)$. The majority $(87.7 \%)$ of the analyzed samples revealed that $\mathrm{pH}$ value met the standard (7.2-7.8). Seventy four (43.5\%) of the samples had TC $>1.1 \mathrm{MPN} / 100 \mathrm{ml}$ and $94.7 \%$ of these samples were positive for fecal coliform.

About half of the samples (49.4\%) showed that free residual chlorine met the Jordanian standards $(1-2 \mathrm{mg} / \mathrm{l})$, while 51 (38.1\%) of the analyzed samples had a concentration of free residual chlorine less than $1 \mathrm{ppm}$. This means that 38\% of the swimming pools have unacceptable level of disinfection or do not comply with the standards limits. Moreover, $43.5 \%$ of the samples were unacceptable with respect to total coliform (> 1.1 MPN/100 m

Table 2: Public Symming Pools sanitary Parameters

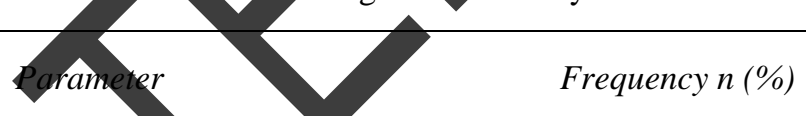

\section{Nater transparency}

Yes
No

$>27^{\circ} \mathrm{C}$

(Required)

$<22{ }^{\circ} \mathrm{C}$

\section{PH Value}

$$
\begin{aligned}
& 7.2-7.8 \quad \text { (Required) } \\
& <7.2 \\
& >7.8
\end{aligned}
$$

Free residual chlorine

$$
\begin{aligned}
& 1-2 \mathrm{mg} / \mathrm{l} \text { (Required) } \\
& <1 \mathrm{mg} / \mathrm{l} \\
& >2 \mathrm{mg} / \mathrm{l}
\end{aligned}
$$

Total coliform

$<1.1 \mathrm{MPN} / 100 \mathrm{ml}$

(Required)

$$
>1.1 \mathrm{MPN} / 100 \mathrm{ml}
$$

\section{Fecal coliform*}

Negative

Positive

$71(94.7)$

$\mathrm{n}=$ Numbers of samples.

* Only in the samples that had TC >1.1 MPN/100 ml. 
Factors Associated with Contamination of Swimming Pools by Total Coliform

Out of 170 samples, $43.5 \%$ had a Total coliform $>1.1$ MPN/100 ml. Factors that were associated with contamination of swimming pools by TC in the multivariate analysis are shown in table 3.

Table 3: Multivariate analysis of factors associated with contamination by Total Coliform.

\begin{tabular}{lcccc}
\hline \multirow{3}{*}{ Factors } & \multicolumn{3}{c}{ Total Coliform } \\
\cline { 2 - 3 } & Total & $n(\%)$ & OR (95\% CI) & $\begin{array}{c}P- \\
\text { Value }\end{array}$ \\
\cline { 2 - 3 } & 170 & $74(44)$ & & \\
\hline
\end{tabular}

Hour of collection

$$
\begin{array}{cccccc}
\text { 12-3 PM } & 111 & 39(35.1) & 1 & \\
3-4 & \text { PM } & 32 & 17(53.1) & 2.91(1.06,8.02) & 0.039 \\
4-5 & \text { PM } & 27 & 18(66.6) & 3.50(1.07,11.14) & 0.038
\end{array}
$$

\begin{tabular}{|c|c|c|c|c|}
\hline Friday & 85 & 30 (35.3) & 1 & \\
\hline Saturday & 85 & $44(51.8)$ & $2.00(2.12,0.95)$ & \\
\hline \multicolumn{5}{|c|}{ Number of swimmers } \\
\hline$<=20$ & 84 & 28 (33.3) & & \\
\hline$>20$ & 86 & 46 (53.5) & & \\
\hline \multicolumn{5}{|c|}{ Temperature } \\
\hline $22-27^{\circ} \mathrm{C}$ & 83 & & & \\
\hline$>27^{\circ} \mathrm{C}$ & 87 & & & 0.011 \\
\hline $1-2 \mathrm{mg} / \mathrm{l}$ & 79 & & 1 & \\
\hline$<1 \mathrm{mg} / \mathrm{l}$ & 61 & 45 (73.8) & $8.29(3.44,19.98)$ & $<0.0001$ \\
\hline$>2 \mathrm{mg} / \mathrm{l}$ & 20 & $06(30.0)$ & $1.00(0.27,3.72)$ & 0.997 \\
\hline \multicolumn{5}{|l|}{ pH value } \\
\hline $7.2-7.8$ & 149 & $63(45.0)$ & 1 & \\
\hline$<7.2$ & 15 & 08 (53.3) & $1.53(0.30,7.81)$ & 0.606 \\
\hline$>7.8$ & 06 & $03(50.0)$ & $0.93(0.13,6.75)$ & 0.941 \\
\hline
\end{tabular}

Day of sampling

OR: Adjusted odds ratio.
Compared with the samples collected at 12:00-3:00 p.m., samples collected at 3:00-4:00 p.m were more contaminated $(\mathrm{OR}=2.91 ; 95 \% \mathrm{CI} 1.06,8.02)$ and samples collected at 4:00-5:00 p.m had higher probability of being contaminated that two types previous samples. $(\mathrm{OR}=3.50$; $95 \%$ CI $1.07,11.14)$ were more likely to have TC $>1.1$ MPN/100 ml. Total coliform was $>1.1 \mathrm{MPN} / 100 \mathrm{ml}$ in $51 \%$ of samples collected on Saturdays and in $35 \%$ of samples collected on Fridays without a statistically significant difference ( $\mathrm{p}$-value $=0.066$ ). Contamination by total coliform was significantly associated with the total number of swimmers of more than 20 persons at the time of sampling (OR=3.15; 95\% CI 1.41, 7.01). Free residual chlorine of less than $1 \mathrm{mg} / \mathrm{h}$-ompared to that of $1-2 \mathrm{mg} / \mathrm{l}$ and water temperature of more than $27^{\circ} \mathrm{C}$ compared to water temperature of $22-27^{\circ} \mathrm{C}$ were significantly associated with increased odds (2.84) of contamination. However, $\mathrm{pH}$ value was not significantly associated with contamination.

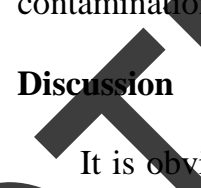

It is obvious from the results that none of the studied imming pools completely comply with the Jordanian Standard for swimming pools especially for health related parameters, $43 \%$ of these pools decline severely from these standards. For free residual chlorine, more than half (50.6\%) of the pools do not comply with the standards. The non complying pools have either higher $(12.5 \%)$ or lower $(38.1 \%)$ than the standards. Thus in the case of lower residual chlorine $(<1 \mathrm{ppm})$ poor disinfection results are expected and they are actually reflected in the microbial contamination of the swimming pools.

The assessment of some physical-chemical aspects, such as free available chlorine, $\mathrm{pH}$ and the swimming pool bathing could predict the quality of pool water. In fact, disinfection of swimming pools should control the organisms responsible for many diseases; however, some microbial contaminations may be relatively protected from disinfection by the filter material or structural features in the pool. Some researchers emphasize that the microbiological quality of swimming pools is best measured by using fecal coliform that indicates fecal contamination [20]. While others consider that the risk of infection is more associated with microorganisms derived from the skin, mouth, and upper respiratory tract of bathers rather than fecal contamination [21]. Some authors consider that microorganisms which indicate hygienic conditions (total coliform and heterotrophic bacteria) and fecal pollution are the best ones [22]. Nevertheless, there are doubts if any microorganism can reliably predict the health risks associated with swimming [14].

\section{Prevalence of Bacterial Contamination}

The TC was $>1.1 \mathrm{MPN} / 100 \mathrm{ml}$ in $43.5 \%$ of water samples and FC was positive in $94.7 \%$ of samples which contained TC $>1.1 \mathrm{MPN} / 100 \mathrm{ml}$. These figures were much higher than that reported in South America where total 
coliform and fecal coliform were $13.3 \%$ and $5.6 \%$ of swimming pools, respectively [14]. In Bologna, Italy, $34.2 \%$ of swimming pools did not conform to the recommended limits for microbiological characteristicsm [23]. The prevalence of contamination among the swimming pools in Amman is much higher than other countries. This can be explained by the finding that none of the swimmers take shower before swimming and most of the swimmers did not disinfect their feet by disinfection liquid before entering the pool.

The prevalence of bacterial contamination in the swimming pools in this study is much higher than that reported by Ministry of Health $(\mathrm{MOH})$ in the same period of the year (Jun - August). This finding may be due to the fact that $\mathrm{MOH}$ Employees collect sample during working days from 9:00 a.m. to 1:00 p.m. In addition, employees in $\mathrm{MOH}$ used to collect their samples from pool surface from any site in the pool (the employees collect the samples in this way because sample collection method is not mentioned in the Jordanian standard). This time of sample collection by $\mathrm{MOH}$ employees does not reflect the actual quality of swimming pools, because most of swimmers swim in the weekend after noon.

Moreover, pools' staff are not doing a proper control process either due to the lack of training of operators or the use of improper method of disinfection as using manual chlorination by un trained operator instead of using automatic disinfection that will produce fixed an continuous chlorine dose. However, the responsibility controlling the quality of the swimming pools does not fall on ministry of health or pool staff alone. Swimmers need to be educated about the necessary hygienic behavio that is needed to prevent or reduce the spread of health hazards.

\section{Factors Associated with Bacteria/Contamination}

Bacterial contamination was significantly associated with the time of sample collection where there was a trend of increase in the prevalence of bacterial contamination with late hours of the day. This may refled a cumulative effect of swinmers as a source of contamination. The number of swimmers of more than 20 persons at the time of sample collection was assøciated with a high prevalence of contanumations, because none of the swimmers take shower before swimming and $97.5 \%$ of swimmers did not disinfect their feet before swimming. The finding is consistent with studies in South America [14]. The cutoff point (20 swimmers) was chosen because nearly half of pools contain more than 20 swimmers. Moreover, a significant association was found between water quality and the numbers of swimmers at this cut off point were water quality was acceptable in swimming pool with less than 20 swimmers.

The pools with a temperature of more than $27^{\circ} \mathrm{C}$ temperature were more likely to be contaminated than pools with a temperature between $22-27^{\circ} \mathrm{C}$. The temperature had direct influence on swimming pool water contamination by increasing microbial growth. The increase in temperature encourages the growth of bacteria. This finding is consistent with other studies $[1,6,14]$.

Free residual chlorine had a significant negative effect on microbiological contamination. Free residual chlorine of less than $1 \mathrm{mg} / \mathrm{l}$ was significantly associated with increased odds (8.29) of contamination. This indicates that chlorine concentration between $1-2 \mathrm{mg} / \mathrm{l}$ is a good operational index to control the quality of swimming pool water as shown by other studies [1, 6, 14]. Although free residual chlorine was available, some pools contained TC $>1.1 \mathrm{MPN} / 100 \mathrm{ml}$; this may reflect recent contamination.

On the other hand, there is no significant association between water $\mathrm{pH}$ value and microbial contamination. This finding may be explained by the small number of pools that had a $\mathrm{pH}<7.2(9 \%)$ and $\mathrm{pH}>7.8$ (4\%). In addition, although there was no significant association between day of sampling and contamination the results indicate that samples collected on Saturdays have increased odds (2.00) of fecal contamination when compared with Friday. This is an indication of ineffective water treatment procedures and the cumulative effect of contannimation. It seems that water treatment does not cope with the increased load of bathers during the weekend days.

\section{Conclusions}

None of the surveyed public swimming pools was in compliance with the Jordanian Standards for Swimming Pools Water 1562/2004.

2. There was a significant association between pools contamination and:

a. Time of sample collection (contamination was highest during the period from 4-5 p.m.).

b. High number of swimmers (more than 20 swimmers in the pool).

c. Water temperature (when it is more than $27^{\circ} \mathrm{C}$ ).

d. Free residual chlorine concentration (when it is less than $1 \mathrm{mg} / \mathrm{l})$.

\section{Recommendations}

Using such swimming pools may result in health hazards for the swimmers. To avoid such hazards the following recommendations are suggested:

1. Better and stricter inspection procedure by the ministry of health should be used. Inspection should be done during the weekends and holidays when the pools are most heavily used.

2. Maintaining proper balance of swimming pool water chemistry especially water chlorination.

3. Continuous monitoring for water quality indicators, (free residual chlorine and temperature) especially when the number of swimmers increases to more than 20 swimmers in the pool.

4. Provide educational signs to advise bathers to:

- Wash their hands with soap and water after using the toilet.

- Take their children to bathroom before swimming. 
5. Refrain from swimming when they have diarrhea or infectious disease.

\section{Reference}

1. Leoni, E.; Legnani, P.; Mucci, M. T.; Pirani, R. Prevalence of mycobacteria in a swimming pool environment. Microbiology, 1999, 87, 683-688.

3. Borgmann-Strahsen, R. Comparative assessment of different biocides in swimming pool water. International Biodeterioration \& Biodegradation. 2003, 51, 291-297.

4. Sato, M. I. Z.; Alves, M. N.; Stoppe, N. C.; Martinys, M. T. Evaluation of Culture Media For Candida Albicans And Staphylococcus Aureus Recovery In Swimming Pool. Pergamon, 1995; 29(10), 2412-2416.

5. Tate, D.; Mawer, S.; Newton, A. Outbreak of Pseudomonas aeruginosa folliculitis associated with a swimming pool inflatable. Epidemiology \& Infection, 2003, 130, 187-192.

6. Fiorillo. L.; Zucker, M.; Sawyer, D.; Lin, A. The Pseudomonas Hot-Foot Syndrome. The New England Journal of Medicine, 2001, 345, 335-338.

7. Leoni, E.; Legnani, P.; Buccisabattini, M. A.; Righi, F. Prevalence of legionella ssp. In swimming pool environment. Pergamon, 2001, 35(15), 3749-3753.

8. Andrey, E.; Floyd, F.; Temothy, A.; Elena, N.; Andry, T.; Ford, F. Serological Evidence of Cryptosporidiur Infections in a Russian City and Evaluation of Ris Factors for Infections. Ann Epidemiol., 2004, 14 129-136.

9. Ekramul, H. M.; Virginia, H.; Tord, K, Robert, S.; Roy, L. Y. Risk of giardiasis in Aucklanders. Int $J$ Infect Dis., 2002, 6, 191-197.

10. Fournier, S.; Dubrou, S.; Ligyory, O.; Gaussin, F.; Santillana, H.; Sarfati, C.; Molina, J. M.; Derouin, F.: Detection of microsporidia, cryptosporidia and giardia in swimming pools. Immunology and Medical Microbiology, 2002, 33, 209-2

11. Ali-Shtayeh, M. S., Tayseer, K.; Khaleel, M.; Rana, J. Ecology of dermatophytes and other keratinophilic fungi in swimming pools and polluted and unpolluted streams. Mycopathologia, 2002, 156, 193-205.

12. Khai, Y.; Roberts, C.; Roberts, J.: Molluscum contagiosum, swimming and bathing. Australasian
Journal of Dermatology, 1999, 40, 89-92.

13. Parent, L; Salam, M.; Appelbaum, P.; Dossett, J. Disseminated Mycobacterium marinum infection and bacteremia in a child with severe combined immunodeficiency. Clinical Infectious Diseases. 1995, 21, 1325-1327.

14. Von Reyn, C. F.; Pestel, M.; Arbeit, R. D. Clinical and epidemiologic implications of polyclonal infection due to Mycobacterium avium complex. Research in Microbiology, 1996, 147, 24-30.

15. Martinys, M. T.; Sato, M. I. Z.; Alves, M. N.; Stoppe, N. C., Prado, V. M.; Sanchez, P. S.: Assessment Of Microbiological Quality For Swimming Pools In South America. Pergamon. 1995, 29(10), 2417-2420.

16. Gonzalez-Mancebo, E.; Gomez, M.; Diez, L.; Pulido, Z.; Alfaya, T; Leon, F.: Swimming-pool pneumonitis. European Journal of Allergy and Clinical Immunology, 2000, 55, 782-783.

17. Deparment of Statistics. Statistical Year Book. Amman Yordan, 2003.

18. Ministry of Health, Department of Environment Health. Amman Jordan 2004.

19. Jordan institution for Standards and Metrology. Jordanian standard for swimming pool water. First edition. Hashemite Kingdom of Jordan. 1562/2004.

20. American Public Health Association, American Water Works Association and Water Environment Federation. Standard Methods for the Examination of Water and Wastewater, 20th ed. Washington, 1998. Esterman, A.; Roder, D. M.; Cameron, A. S.; Robenson, B. S.; Walters, R. P,.; Lake, J. A.; and Christy, P. E. Determinants of the Microbiological Characteristic of South Australian Swimming Pools. Appl. Environ. Microbial, 1984; 47, 325-328.

22. Mossel, D. A.: Microbiological markers for swimming-Associated infectious health hazard. Am. J. Publ. Hlth. 1986, 67, 297.

23. Araujo, M. A.; Guimaraes, V. F.; Mendonca-Hagler, L. C. S.; Hagler, A. N.: Staphylococcus aureus fecal streptococci in fresh and marine surface water of Rio De Janeiro, Brazil. Rev. Microbio. 1990, 21, 141-147.

24. Leoni, E. Legnani, P. Guberti, E.; Masotti, A.: Risk of infection associated with microbiological quality of public swimming pools in Bologna, Italy. Public Health, 1999, 113, 227-232. 